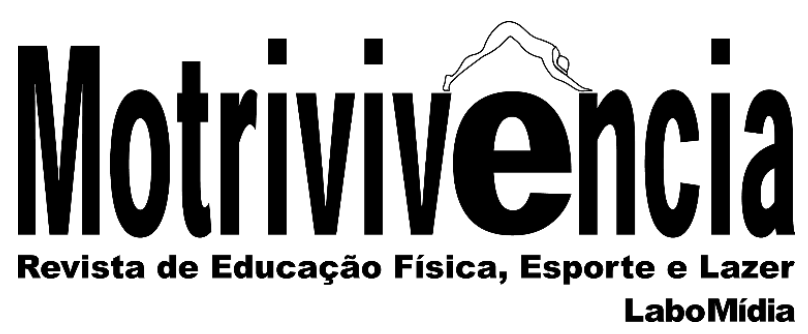

\title{
Repensando as relações de gênero nas vivências do ultimate frisbee na escola
}

\begin{abstract}
RESUMO
Este artigo traz reflexões de como as relações de gênero foram vivenciadas, problematizadas e modificadas na realização do projeto "Ultimate Frisbee: vivências e reflexões táticas utilizando recursos midiáticos nas aulas de educação física". A discussão de gênero surgiu durante as aulas, em virtude deste esporte ser composto oficialmente pela categoria mista, em que meninos e meninas jogaram juntos, gerando conflitos que precisaram ser discutidos e repensados. Para tanto, foram buscados fundamentos nos Estudos Feministas e de Gênero na tentativa de compreender as problemáticas que emergiram com a realização das aulas práticas.
\end{abstract}

PALAVRAS-CHAVE: Frisbee; Gênero; Educação física; Escola
Ana Aparecida Tavares da Silveira Mestranda em Educação

Universidade Federal do Rio Grande do Norte - UFRN, Departamento de Educação,

Natal, Rio Grande do Norte, Brasil. anatalats@gmail.com (D) https://orcid.org/0000-0001-6232-1940

Maria Aparecida Dias

Doutora em Educação

Universidade Federal do Rio Grande do Norte - UFRN,

Departamento de Educação Física, Nata, Rio Grande do Norte, Brasil. cidaufrn@gmail.com (D) https://orcid.org/0000-0003-3644-604X 


\title{
Rethinking gender relations under the experience of Ultimate Frisbee activities in the school
}

\begin{abstract}
This article addresses how gender relations were experienced, questioned and modified during the project "Ultimate Frisbee: the experiences and reflections of the tactics using media resources in physical education classes." The discussion of gender came up during the classes for this sport is officially composed of a mixed gender category, in which boys and girls play together. Hence, some conflicts needed to be discussed and reconsidered. For this purpose, the fundamentals of Feminist and Gender Studies were applied in an attempt of understanding the problems that emerged with the implementation of these classes.
\end{abstract}

KEYWORDS: Frisbee; Gender; Physical education; School

\section{Repensando las relaciones de género en las experiencias de Ultimate Frisbee en la escuela}

\section{RESUMEN}

Este artículo trae algunas reflexiones de cómo las relaciones de género fueron experimentadas, problematizadas y modificadas en la realización del proyecto "Ultimate Frisbee: experiencias y reflexiones tácticas usando recursos de medios en clases de educación física". La discusión del género surgió durante las clases bajo ese tipo de deporte, que es oficialmente constituido por la categoría mixta, en que niños y niñas jugó juntos, generando conflictos que necesitaban ser discutidos y repensados, cuyos motivos fueron buscados en los Estudios Feministas y Género en el intento de comprender los problemas que surgieron con la realización de clases prácticas.

PALABRAS-CLAVE: Frisbee; Género; Educación física; Escuela 


\section{CONTEXTUALIZANDO AS AULAS}

A educação, em consonância com as mudanças econômicas, políticas e sociais que ocorrem no mundo globalizado, vem se modificando para responder a novas demandas. As aulas de educação física no Brasil eram, até o final de 2017, norteadas pela Lei de Diretrizes e Bases da Educação Nacional ((LDB, Lei nº 9.394/1996), que objetivava oportunizar aos sistemas de ensino a preparação do educando para o exercício da cidadania e sua qualificação para o trabalho, utilizando os princípios de liberdade e os ideais de solidariedade humana presentes na Constituição Federal de 1988 (BRASIL, 1996).

Em outubro de 2015, iniciou-se a consulta pública para a construção da primeira versão da nova Base Nacional Comum Curricular (BNCC), que passou a ser o novo documento de caráter normativo para definir o conjunto orgânico e progressivo de aprendizagens essenciais que todos os alunos devem desenvolver ao longo das etapas e das modalidades da Educação Básica. A BNCC deverá nortear os currículos dos sistemas e das redes de ensino das Unidades Federativas, como também as propostas pedagógicas de todas as escolas públicas e privadas de Educação Infantil, Ensino Fundamental e Ensino Médio, em todo o Brasil (BRASIL, 2017).

A BNCC, assim como a LDB, traz a compreensão da educação física articulada à área da linguagem. Todavia, modifica a abordagem dos seus conteúdos, categorizando-os como práticas corporais tematizadas, compostas por seis unidades temáticas (Brincadeiras e jogos; Esportes; Ginásticas; Danças; Lutas e Práticas corporais de aventura) que deverão ser ministradas ao longo do Ensino Fundamental. $\mathrm{Na}$ unidade temática Esporte, podemos encontrar o Ultimate Frisbee, classificado como esporte de invasão:

Invasão ou territorial: conjunto de modalidades que se caracterizam por comparar a capacidade de uma equipe introduzir ou levar uma bola (ou outro objeto) a uma meta ou setor da quadra/ campo defendida pelos adversários (gol, cesta, touchdown etc.), protegendo, simultaneamente, o próprio alvo, meta ou setor do campo (basquetebol, frisbee, futebol, futsal, futebol americano, handebol, hóquei sobre grama, polo aquático, rúgbi etc) (BRASIL, 2017, p. 214).

Os Esportes também podem se subdividir em categorias: Marca; Precisão; Técnicocombinatório; Rede/quadra dividida ou parede de rebote; Campo e taco; Invasão ou territorial e Combate. Essas novas classificações utilizam um modelo "baseado na lógica interna, tendo como referência os critérios de cooperação, interação com o adversário, desempenho motor e objetivos táticos da ação" (BRASIL, 2017, p. 213), mas essa categorização não aponta para uma 
universalidade da abordagem do esporte, e sim oferece possibilidades, um novo olhar para compreensão das manifestações culturais esportivas (BRASIL, 2017).

A proposta da nova BNCC para a Educação Física foi assunto das formações continuadas dos professores dessa disciplina na rede municipal de ensino da cidade do Natal. Participei das reuniões discutindo, vivenciando e construindo contribuições, e foi a partir de então que minhas aulas começaram a sofrer influência dos novos conhecimentos propostos nas unidades temáticas desse documento. Uma das primeiras categorias que foi trabalhada foi o esporte de invasão, trazendo o Ultimate Frisbee como manifestação cultural esportiva a ser explorada.

O Ultimate Frisbee é realizado com duas equipes que disputam entre elas a conquista de pontos ao invadir a área do adversário e receber o disco na área de pontuação. A história mais aceita sobre o surgimento desse esporte aponta para os Estados Unidos por volta de 1960, quando estudantes de uma universidade do estado da Pensilvânia começaram a brincar com uma fôrma de torta de uma fábrica, lançando-a entre eles. O nome dessa fábrica era Frisbie's Pies, o que denominou o esporte. No Brasil, chegou na década 80 e tornou-se atrativo pela simplicidade de suas regras e por não necessitar de materiais caros (FEDERAÇÃO PAULISTA DE DISCO, 2017).

O Frisbee, nome mais popular, faz parte dos conhecimentos da Cultura de Movimento ${ }^{1}$, que se amplia na escola para além dos esportes tradicionalmente mais praticados como o Voleibol, Basquetebol, Handebol, Futsal, entre outros. Diferencia-se, além das suas características específicas, por oferecer a possibilidade de se jogar com outro objeto, que não a bola, com um disco, em equipes mistas e sem árbitro. Essas peculiaridades tornam esse esporte diferente, em muitos aspectos, dos demais, produzindo um campo de construção de conhecimento que traz novas discussões para além das regras, dos recursos materiais e das violações intencionais ocorridas no jogo, pois apresenta um código de honra e respeito mútuo entre os participantes, sendo os mesmos estimulados a respeitar os princípios do jogo e a praticarem o fair play (jogo limpo). Isso se torna possível, tendo em vista que os próprios jogadores julgam a intencionalidade de suas ações e discutem a melhor solução para cada situação problema (BORGES et al, 2014).

O projeto "Ultimate frisbee: vivências e reflexões táticas utilizando recursos midiáticos nas aulas de educação física" aconteceu na Escola Municipal Professora Maria Cristina Osório Tavares, localizada no bairro de Felipe Camarão, periferia da cidade do Natal/RN, em parceria com o Laboratório de Educação Física e Mídia (LEFEM) do curso de Educação Física da Universidade Federal do Rio Grande do Norte, que forneceu a maior parte dos recursos midiáticos (câmera Go

\footnotetext{
${ }^{1}$ Termo utilizado pelo professor Eleonor Kunz no livro Educação Física: ensino \& mudanças. Ijuí: Unijuí, 1991, para organizar o conhecimento próprio da Educação Física escolar. Com esse termo, Kunz reconhece as significações culturais e a intencionalidade do movimento humano, problematizando a concepção mecanicista de corpo e de movimento.
} 
Pro e tablets), utilizados pelos alunos para registrar as aulas, e disponibilizou um estagiário², que colaborou com o planejamento, a realização das aulas, o arquivamento e a edição das imagens.

As aulas foram realizadas em duas turmas mistas compostas por alunos do $5^{\circ}$ ano $\mathrm{A}$ e $\mathrm{B}$ do Ensino Fundamental do turno matutino, com faixa etária entre nove e treze anos de idade e teve como objetivo principal refletir sobre as vivências táticas do Ultimate Frisbee a partir de imagens midiáticas produzidas mediante experiências dos alunos.

Iniciamos o estudo desse conteúdo abordando aspectos referentes à história, às regras e às peculiaridades do esporte. Em seguida, fabricamos discos com materiais alternativos e experimentamos. Então, passamos para as vivências do jogo e da utilização dos recursos midiáticos. Três aulas foram filmadas e fotografadas pelas próprias crianças, utilizando cinco tablets, uma câmera Go Pro e os celulares de todos que possuíam. Os jogos, registrados de vários ângulos e por vários alunos ao mesmo tempo, em um esquema de rodízio, no qual uns filmavam, alguns fotografavam e outros jogavam. Em duas aulas consecutivas foram realizadas as apreciações das produções midiáticas e as análises táticas editadas em um vídeo no Movie Make . Para análises táticas, foram selecionadas algumas imagens vistas por vários ângulos. Nessas imagens, avaliou-se as táticas utilizadas pelas equipes; além disso, também foi possível refletir sobre algumas outras questões que surgiram nas rodas de conversa no final das aulas: Como ocorreram as resoluções das situações de conflito provocadas pelo jogo, sem a interferência da professora ou de um juiz? Como se desenvolveram o trabalho em equipe, a honestidade, o senso de justiça? Houve prazer em jogar? Houve adaptações para promover a inclusão de todos nas aulas? Como foi jogar em equipes mistas? E houve igualdade, respeito e cooperação na participação de meninos e meninas nas aulas?

Esses questionamentos trouxeram outras possibilidades de pensar o esporte nas aulas, extrapolando o objetivo principal do projeto, que era refletir sobre as táticas utilizadas pela turma na prática do Frisbee. Todavia, foram as três últimas questões acima que me motivaram a refletir e escrever, e com as quais tentarei me aprofundar.

Para realizar a prática do Ultimate Frisbee como esporte, utilizei várias estratégias: uma delas foi dividir os alunos em quatro equipes mistas, o que resultou em duas partidas sendo jogadas ao mesmo tempo com a mesma turma, e algumas crianças registrando as imagens. Embora a estratégia tenha sido a mesma, foram perceptíveis duas realidades distintas de participação dos meninos e das meninas no jogo, comparando as duas turmas dos $5^{\circ}$ anos.

No $5^{\circ} \mathrm{A}$, haviam doze meninas e dezenove meninos e, mesmo compondo as equipes de forma mista, o número de meninas era sempre menor nas formações, o que favoreceu a hegemonia

\footnotetext{
${ }^{2}$ Diogo Felipe Frazão.

${ }^{3}$ Software da Microsoft de edição de vídeos.
} 
da posse do disco aos meninos. Os alunos não compartilharam de forma igualitária a posse do disco com ambos os sexos, os fizeram com os colegas e apenas com aquela colega mais habilidosa, se houvesse uma no time. Assim, as meninas passaram boa parte do tempo sem participar dos lances do jogo, sentindo-se excluídas e desmotivadas. Percebo aqui uma problemática que desejo refletir: a histórica exclusão feminina no âmbito público, em especial nas práticas corporais esportivas.

No $5^{\circ} \mathrm{B}$, a turma era composta por quatorze meninas e quinze meninos, o que facilitou uma divisão sexual equiparada, resultando na participação ativa das meninas no jogo. Entretanto, outra situação relevante para discutir gênero foi percebida: as atitudes intimidadoras dos meninos frente às meninas. Como eles estavam distribuídos em números iguais no time e precisavam das meninas para fazer pontos, compartilharam o disco no ataque e na defesa, diferentemente dos garotos da outra turma, mas utilizaram-se de gritos e de contatos físicos violentos, como empurrões, para se impor diante delas, assim como ocorria entre os meninos do $5^{\circ} \mathrm{A}$, resultando em quedas e machucados.

Notamos, nas aulas dessa última turma, duas problemáticas que estão intrinsecamente conectadas entre elas, como também se liga à problemática da primeira turma. A primeira, diz respeito à naturalização dicotômica do comportamento tido como nato nas mulheres, o de ser menos habilidosas no esporte e menos agressivas, diferentemente dos meninos, que são considerados habilidosos, fortes e agressivos; a segunda, toma como referência a condição biológica na construção de identidades ligadas à masculinidade e à feminilidade hegemônicas, que serviu para aprisionar homens e mulheres a modelos padrões, excluindo as mulheres das atividades físicas.

Escreva agora a Introdução. Demonstre aqui a validade do objetivo do estudo. Dê ao leitor informações necessárias para que ele entenda o objetivo e a validade (importância) do estudo (VOLPATO, 2007). Nos próximos parágrafos trata-se da apresentação da formatação do texto.

\section{PRÁTICAS CORPORAIS E DESIGUALDADES ENTRE GÊNEROS}

As relações de gênero aqui abordadas partiram da compreensão dos princípios de igualdade e equidade, por entender que todos devem ter garantido a dignidade e a possibilidade de participar das aulas enquanto cidadãos de direitos. Esses princípios estão presentes nos Temas Transversais dos Parâmetros Curriculares Nacionais ( $\mathrm{PCN}^{\prime} \mathrm{s}$ ) ligados a ética em sua esfera moral, trazendo a idéia de justiça:

[...] é sensato pensar que as regras que organizem a convivência social de forma justa, respeitosa e solidária têm grandes chances de serem seguidas. De fato, a 
justiça permite que as oportunidades sejam iguais para todos, sem privilégios que, de partida ou no meio do caminho, favoreçam alguns em detrimento de outros. Se as regras forem vistas como injustas, dificilmente serão legitimadas (BRASIL, 1997, p.54).

Desta maneira, pensar em gênero a partir da igualdade passa pela compreensão de que todos os alunos e alunas têm os mesmos direitos e, portanto não há razão para que alguns sejam mais iguais que outros. Pensar gênero a partir da equidade é entender que na grande maioria das vezes, as pessoas não se encontram em posição de igualdade, pois nascem com diferentes talentos, em diferentes condições sociais, econômicas, físicas, entre outras. Assim, é preciso garantir direitos de igualdade, considerando as diferenças.

Embora essa discussão de igualdade e equidade venha contribuindo para pensar as relações de gênero na escola, muito pouco ou quase nada mudou, é o que aponta o Plano Nacional de Políticas para as Mulheres 2013-2015: “a educação brasileira ainda não incorporou totalmente o principio da igualdade de gênero", pois discutir gênero não se resume a igualdade e garantia de direito de acesso de alunos dos sexos masculinos e femininos a escola, vai muito além, a que se perceber "diferenças nos conteúdos educacionais, nos cursos e nas carreiras acessados por mulheres e homens", que ainda permanecem sendo tratados de forma desigual (BRASIL, 2013, p.22):

A escola acaba reproduzindo a desigualdade vivida entre as pessoas na sociedade, seja nos currículos, nos livros didáticos, nas práticas das salas de aula ou nos procedimentos de avaliação. A linguagem sexista dos textos e práticas cotidianas, a invisibilidade das mulheres na ciência e na história responde à ideologia patriarcal e ao androcentrismo do conhecimento; estes são denunciados como um dos elementos da construção da desigualdade de gênero. [...] Muitas ações e programas são hoje executados, mas urge o fortalecimento dessas ações, no âmbito da educação, de modo a contribuir para uma educação igualitária e sem discriminação no ambiente escolar.

Complementando essas concepções postas à educação, O Plano Nacional de Políticas para as Mulheres 2013-2015 propõe uma série de metas, linhas e planos de ação que visam mudar a desigualdade das relações sociais entre homens e mulheres. Trás também como um de seus objetivos "estimular, ampliar e qualificar o acesso de meninas, adolescentes, mulheres adultas, idosas e mulheres com deficiência ao esporte e ao lazer, promovendo a qualidade de vida, a inclusão social, a cidadania e o desenvolvimento humano" (BRASIL, 2013, p.75).

Tentando contribuir com esses objetivos acima descritos, buscamos repensar a prática pedagógica a partir das aulas de Ultimate Frisbee nas aulas de educação física, tentando transformála, tendo em vista que o esporte está inserido em uma estrutura social gendrada de valores e normas 
androcêntricas que são construídas "a partir das experiências, perspectivas e vozes das mulheres como grupo subalterno, reconhecendo-se sua diversidade" (CARVALHO e RABAY, 2015, p.123).

O respeito à diversidade é atualmente um dos pontos mais discutidos como essencial na busca de uma educação de qualidade. Assim, é fundamental compreender que meninos e meninas de uma mesma escola "têm histórias de vida, condições sócio-econômicas, experiências motoras, acervo cultural e interesses distintos", o que resulta em uma diversidade de modos de ser que deve ser respeitado e que não pode se restringir a um olhar puramente biológico da compreensão de gênero (DORNELLES e FRAGA, 2009, p.148).

A interferência da cultura presente nos estudos das técnicas do corpo de Mauss (2003, p.204) contribuiu para modificar a visão da aprendizagem dos corpos em movimento, antes apoiados pelo determinismo biológico, passam a compreender que os “"hábitos" variam não simplesmente com os indivíduos e suas imitações, variam sobretudo com as sociedades, as educações, as conveniências e as modas, os prestígios".

Outra concepção que também amplia essa compreensão é a fenomenologia do filósofo Merleau-Ponty presente em muitos dos estudos de Nóbrega. Para a autora "nosso corpo traz marcas sociais e históricas, portanto questões culturais, questões de gênero, de pertencimentos sociais podem ser lidas no corpo" (NÓBREGA, 2005, p. 605). Isso ocorreu em uma das minhas aulas, quando, ao compartilhar as experiências do Ultimate Frisbee inseridos no contexto de turmas mistas, alguns meninos conseguiram apontar, antes que eu tivesse realizado alguma intervenção, que as habilidades no jogo não dependem exclusivamente das características biológicas ligadas ao sexo, mas ao interesse e a oportunidade que cada um teve e tem de se movimentar. Um aluno disse: “Assim como tem meninas que jogam pouco, também tem meninos do mesmo jeito. Não é o fato de ser menina que impede ela de saber jogar." Como essa visão não era a da maioria dos meninos, predominando a nítida divisão sexual, a valorização da agilidade, da competência e da superioridade masculina frente à incompetência feminina, foi primordial ter surgido, pois promoveu uma rica discussão sobre determinismo biológico, gênero, cultura, inclusão, diversidade e direitos.

De acordo com Piscitelli (1998), numa leitura de gênero, é primordial explorar as complexidades, tanto das construções de masculinidade quanto das de feminilidade, entendendo como essas construções são utilizadas como operadores metafóricos para o poder e a diferenciação em diversos aspectos do social.

Segundo Grossi (2004), na cultura ocidental, uma das principais definições de masculinidade está relacionada ao fato de o homem ser sujeito ativo nas relações sexuais, ou seja, no senso comum ele deve penetrar o corpo do outro sexualmente. Porém, a identidade de gênero masculino não se constitui apenas com a incorporação do macho ativo ou pela atividade sexual, mas 
também pela hiperatividade dos meninos na infância e se confunde seguidamente com agressividade. A masculinidade ativa está diretamente ligada à agressividade, sendo equivocada a ideia de senso comum, compartilhada na escola pelos professores, funcionários, gestores e entre os pais, que os meninos são hiperativos e hiperagressivos com as colegas de sala porque nasceram assim. A agressividade não é uma característica inata do sexo masculino, nem é um comportamento que se deve esperar como sendo natural do mesmo, é um ritual no qual se aprende a se construir a masculinidade, separando-se do universo feminino.

Conforme o mesmo autor, existem inúmeros rituais de iniciação da masculinidade. Para compreender a realidade brasileira, traz o estudo de Daniel Welzer Lang que discute a constituição da masculinidade através da violência, comparando as sociedades tribais com as ocidentais. Lang mostra que nas sociedades tribais existem a "casa dos homens", espaço de convívio apenas masculino localizado no centro das aldeias, em que os meninos frequentam durante todo o seu crescimento e onde aprendem a se tornar masculinos. Em analogia às sociedades tribais, nas ocidentais a "casa dos homens" pode ser inúmeros lugares, como exemplo, cita as práticas esportivas masculinas.

Embora o Ultimate Frisbee não seja um esporte jogado exclusivamente por homens, a presença masculina o torna um lugar central na constituição da masculinidade dos alunos, podendo ser repensado nas aulas de educação física, de modo que sejam desnaturalizadas as atitudes dos alunos e questionadas as relações de gênero que são construídas cotidianamente nas aulas.

Essa abordagem sobre os rituais de masculinidade ao qual venho discutindo está associada ao conceito de uma determinada forma hegemônica de masculinidade, que distancia o comportamento dos homens do comportamento das mulheres, interiorizando uma norma social de interesses masculinos. Todavia, entendo a partir de Connel (1995, p.188), que:

A masculinidade é uma configuração de prática em torno da posição dos homens na estrutura das relações de gênero. Existe, normalmente, mais de uma configuração desse tipo em qualquer ordem de gênero de uma sociedade. Em reconhecimento desse fato, tem-se tornado comum falar de "masculinidades". Existe o perigo, nesse uso, de que possamos pensar no gênero simplesmente como um pout-pourri de identidades e estilos de vida relacionados ao consumo. Por isso, é importante sempre lembrar as relações de poder que estão aí envolvidas.

Assim, mesmo que tenha abordado a masculinidade em sentido mais convencional, é imprescindível perceber que há outras masculinidades agrupadas, produzidas no mesmo contexto social e que também foram identificadas nas turmas dos $5^{\circ}$ anos. Alguns alunos não apresentavam características agressivas, nem demonstravam muitas habilidades no jogo e outros não 
demonstravam grande interesse pelo esporte, e sim pelos equipamentos midiáticos. Aqui surgiram outras situações que envolviam as relações de gênero das múltiplas masculinidades e que foram discutidas com a turma, indicando que há diferentes formas de sentir, usar e mostrar os corpos masculinos.

Essas situações que comprometeram a participação e a aprendizagem dos alunos foram discutidas nas rodas de conversas realizadas no final da aula. Em um desses momentos, discutimos como poderíamos garantir a participação dos alunos menos habilidosos no jogo. Após algumas sugestões, decidimos que a marcação do ponto no jogo só iria valer se, a cada ataque, o disco passasse por todos da equipe. A participação também foi garantida através do sistema de rodízio realizado entre jogar e registrar as imagens, de modo que todos vivenciariam as atividades realizadas, garantindo que houvesse experimentação.

Em outro momento da roda de conversa, as meninas expressaram oralmente a insatisfação com a agressividade utilizada pelos meninos durante os jogos. Sugeriram então a formação de equipes compostas apenas por meninas para jogar entre elas, contrariando as regras do esporte, que sugere equipes mistas. Por alguns momentos, me senti propensa a aceitar a sugestão, pois equivocadamente tinha a intenção de protegê-las da agressividade dos meninos, mas após algumas trocas de conhecimentos com outros professores de Educação Física e algumas leituras sobre relações de gênero e sexualidade, percebi que na realidade eu não iria protegê-las, iria sim aumentar o abismo que as separa dos meninos na igualdade de oportunidades e conhecimento. Portanto, cabe perceber aqui como a mulher é responsável pela construção da sua própria história.

Segundo Haraway (2004), o paradigma da identidade de gênero surgiu com os funcionalistas burgueses e os existencialistas pré-feministas no período do pós-guerra, com a problematização de Simone de Beauvoir de que não se nasce mulher, questionando o que era anteriormente naturalizado. A partir de então, as discussões sobre gênero tiveram historicamente uma multiplicidade de discursos, posições e sentidos. Nessa jornada, as feministas se opuseram ao "determinismo biológico", que definia a mulher como do sexo feminino em função dos seus atributos biológicos, em favor do "construcionismo social", que removia as mulheres da categoria da natureza para inseri-las na cultura como sujeitos sociais na história. Desta forma, homens e mulheres passam a ser vistos como pessoas produzidas pelo gênero, produto do trabalho da cultura sobre a biologia. Todavia, para feministas-socialistas alemãs deve-se tomar cuidado para não permitir que o construcionismo social na questão de gênero se torne uma teoria de determinismo fechado, pois apesar de sua situação ser definida pela cultura, há a possibilidade de resistência. 
Esta literatura examina como as mulheres constroem a si mesmas no interior de estruturas existentes, de modo a encontrar o ponto no qual seja possível a mudança. Se as mulheres são teorizadas como vítimas passivas do sexo e do gênero como um sistema de dominação, nenhuma teoria da liberação seria possível (HANAWAY, 2004, p.207).

Portanto, as meninas não são vítimas passivas da agressividade dos meninos, pois questionam e resistem, tentando mudar a realidade vivenciada. Acredito que o caminho que apontaram em jogar separadamente dos meninos não foi o mais adequado, assim, sugeri a possibilidade da realização do jogo misto, em que pudessem jogar com todos em condições de igualdade. Todavia, para que isso acontecesse, foram necessárias algumas mudanças no jogo.

Uma solução possível que construímos foi à criação de uma regra para aumentar a penalidade da falta com contato físico ${ }^{4}$ ou pela intimidação oral. Quem provocasse o contato físico intencional ou a intimidação oral ficava fora do jogo por dois minutos, caso reincidisse, seria expulso. O resultado apareceu de forma lenta, mas fez toda a diferença para as crianças. O jogo fluiu melhor, com a participação dos meninos e das meninas juntos, e foi possível garantir a igualdade desejada. Essa mudança só foi possível pela participação ativa das meninas, relatando os problemas enfrentados e pela disposição de lutarem pelos seus direitos de praticar o esporte de forma prazerosa.

\section{CONSIDERAÇÕES FINAIS}

O movimento feminista contribuiu e ainda contribui muito para as discussões de gênero, levando para esfera política, como ressalta Bourdieu (1999), assuntos discutíveis ou contestáveis e preocupações afastadas ou ignoradas pela tradição política por parecer pertencer ao mundo privado e, em muitas situações, estão ligadas ao inconsciente masculino e feminino, levando a uma perpetuação das relações sociais de dominação. Para Bourdieu (1999, p.139):

Só uma ação política que leve realmente em conta todos os efeitos de dominação que se exercem através da cumplicidade objetiva entre as estruturas incorporadas (tanto entre as mulheres quanto entre os homens) e as estruturas de grandes instituições em que se realizam e se produzem não só a ordem masculina, mas também toda a ordem social (a começar pelo Estado, estruturado em torno da oposição entre sua "mão direita", masculina, e sua "mão esquerda", feminina, e a Escola, responsável pela reprodução efetiva de todos os princípios de visão e de divisão fundamentais, e organizada também em torno de oposições homólogas) poderá, em longo prazo, sem dúvida, e trabalhando com as contradições inerentes

\footnotetext{
${ }^{4} \mathrm{O}$ contato físico é uma regra do jogo que não é permitida, dá direito de posse do disco à equipe adversária, caracterizando-se como falta.
} 
aos diferentes mecanismos ou instituições referidas, contribuir para o desaparecimento progressivo da dominação masculina.

Cabe, assim, repensar a posição da escola na construção das relações de gênero, e, sobretudo, na minha posição enquanto educadora e figura de prestígio para os alunos, buscando oportunizar discussões pertinentes ao tema e as mesmas condições de aprendizagens para toda turma, entendendo que há múltiplas subjetividades e que as técnicas do corpo não são natas, mas adquiridas por meio de múltiplos fatores que sofrem interferência da cultura. Embora o mundo social construa "o corpo como realidade sexuada e como depositário de princípios de visão e de divisão sexualizantes", como defende Bourdier (1999, p.18), é necessário compreender esse processo e tentar romper com esse caminho.

O acesso da mulher ao esporte no Brasil não chegou de forma igualitária para todas, assim como na atualidade ainda não o é. Ao refletir sobre a participação feminina nos jogos Olímpicos de Atenas em 2004, Goellner (2005) afirma que, embora a delegação brasileira tivesse apresentado um número de mulheres atletas quase igual ao dos homens, isso não quer dizer que as condições de acesso ao esporte e às práticas corporais das mulheres e dos homens são as mesmas. A história das práticas corporais nacionais, sejam como atividades de alto rendimento, como lazer, como educação física escolar ou como qualquer outra particularidade, mostra que foram e são distintos os incentivos oferecidos às mulheres.

Dessa forma, percebo que muitos são os conflitos vivenciados nas aulas de educação física para oportunizar o acesso ao esporte para as meninas e muitos outros extrapolam as aulas, como é o caso dos jogos escolares, em que a maioria das modalidades esportivas não são praticadas por meninos e meninas em equipes mistas. O determinismo biológico ainda é o referencial predominante, que os segregam em categorias feminino e masculino. Isto reforça a segregação sexual, mas também traz a possibilidade de problematizar junto aos alunos a homogeneidade física como fator determinante para separá-los por sexo nas modalidades esportivas. Em consonância com Dornelles, Fraga (2009), defendemos que, se as turmas tiverem de ser organizadas por alunos com o mesmo perfil, outras características também devem ser consideradas: idade, força e habilidade de cada aluno ou aluna. Mas isso não é possível, pois não há homogeneidade e os próprios alunos apontaram isso.

Refletir sobre as relações de gênero nas aulas de Ultimate Frisbee me permitiu ir além das problemáticas enfrentadas pelas meninas durante as aulas práticas, trouxe a possibilidade de reformular o conhecimento, expandir a compreensão e criar novas situações para o exercício, tentando envolver todos nas aulas de educação física e potencializando questionamentos acerca de 
especificidades femininas e masculinas, de homens e mulheres, que nos conduza para novas trajetórias, para uma nova relação de gênero mais igualitária.

\section{REFERÊNCIAS}

ADELMAN, Miriam. Mulheres atletas: re-significações da corporalidade feminina. Trabalho apresentado na XXIII Reunião Anual da ANPOCS, em Caxambu, MG, em outubro de 1999.

BRASIL. Lei de Diretrizes e B. Lei no 9.394/96, de 20 de dezembro de 1996. Estabelece as Diretrizes e Bases da Educação Nacional. Diário Oficial da União, Brasília, DF, v. 11, 2015.

BRASIL. Ministério da Educação. Base Nacional Comum Curricular. Brasília, DF, 2017.

BRASIL. Presidência da República. Secretaria de Políticas para Mulheres. Plano Nacional de Políticas para as Mulheres 2013-2015. Brasília: Secretaria de Políticas paras Mulheres, 2013. 114 p.

BRASIL. Secretaria de Educação Fundamental. Parâmetros curriculares nacionais: educação física / secretaria de educação fundamental. - Brasília: MEC/SEF, 1997. 96p.

BORGES, Robson Machado; OLIVEIRA, João Danilo Batista de; SANTOS, Admilson; FARIAS, Sandra Regina Rosa. Ultimate Frisbee. In: GONZÁLEZ, Fernando Jaime; DARIDO, Suraya Cristina; OLIVEIRA, Amauri Aparecido Bássoli. (Orgs.) . Práticas Corporais e a organização do conhecimento: esportes de invasão: basquetebol, futebol, futsal, handebol, ultimate frisbee. Maringá: Eduem, 2014. 326p.

BOURDIEU, Pierre. A Dominação Masculina. Rio de Janeiro: Bertrand, 1999.

CARVALHO, Maria Eulina Pessoa de; RABAY, Glória. Usos e incompreensões do conceito de gênero no discurso educacional no Brasil. Estudos Feministas, Florianópolis 23 (1), p.119-136, Janeiro-abril/2015.

CONNEL, Robert. Políticas da masculinidade. Educação e realidade, 20(2), jul/dez. 1995, 185206.

DORNELLES, Priscila Gomes; FRAGA, Alex Branco. Aula mista versus aula separada? uma questão de gênero recorrente na educação física escolar. Revista Brasileira de Docência, Ensino e Pesquisa em Educação Física - ISSN 2175-8093 - Vol. 1, n. 1, p.141-156, Ago., 2009.

FEDERAÇÃO PAULISTA DE DISCO. Cartilha Explicativa - Ultimate Frisbee. Disponível em: http://docs.wixstatic.com/ugd/631120 82c7add96bf94572b1cf9d05f0701441.pdf. Acesso em: 06 maio 2017.

FRASER, Nancy. O feminismo, o capitalismo e a astúcia da História. Mediações, vol. 14, número 3, 2009, p.11-32. 
GOELLNER, Silvana Vilodre. Mulher e esporte no Brasil: entre incentivos e interdições elas fazem história. Pensar a Prática Vol.8 N.1, jan/jun, 2005.

GOELLNER, Silvana Vilodre; FRAGA, Alex Branco. O espetáculo do corpo: mulheres e exercitação física no início do século XX. In: CARVALHO, Marie Jane Soares.; ROCHA, Cristianne. M. F. Produzindo Gênero. Porto Alegre: Sulina, 2004, p.161-171.

GROSSI, Miriam Pillar. Masculinidades: uma revisão teórica. Antropologia em primeira mão. UFSC, 2004. Disponível em: http://www.antropologia.ufsc.br/75.\%20grossi.pdf. Acesso em: 14 Jun. 2017

HARAWAY, Donna. Gênero para um dicionário marxista: a política sexual de uma palavra. Cadernos. Cadernos Pagu. (22) 2004, p.201-246.

MAUSS, Marcel. As técnicas do corpo. Sociologia e antropologia. São Paulo: Cosac Naify, 2003.

NÓBREGA, Terezinha Petrucia da. Qual o lugar do corpo na educação? Notas sobre conhecimento, processos cognitivos e currículo. Educação e Sociedade. Campinas, vol. 26, n. 91, p. 599-615, Maio/Ago, 2005.

PISCITELLI, Adriana. Gênero em Perspectiva. Cadernos Pagu (11) 1998. p.141-155.

\section{NOTAS DE AUTOR}

\section{AGRADECIMENTOS}

Dra. Rozeli Maria Porto - Professora do Departamento de Antropologia (DAN) e do Programa de Pós-Graduação em Antropologia Social (PPGAS) da Universidade Federal do Rio Grande do Norte/UFRN.

\section{CONTRIBUIÇÃO DE AUTORIA}

Não se aplica.

\section{FINANCIAMENTO}

Não se aplica.

\section{CONSENTIMENTO DE USO DE IMAGEM}

Não se aplica.

\section{APROVAÇÃO DE COMITÊ DE ÉTICA EM PESQUISA}

Não se aplica. 


\section{CONFLITO DE INTERESSES}

Não se aplica.

\section{LICENÇA DE USO}

Os autores cedem à Motrivivência- ISSN 2175-8042 os direitos exclusivos de primeira publicação, com o trabalho simultaneamente licenciado sob a Licença CreativeCommonsAttribution NonComercial ShareAlike (CC BY-NC SA) 4.0 International. Estra licença permite que terceirosremixem, adaptem e criem a partir do trabalho publicado, desde que para fins não comerciais, atribuindo o devido crédito de autoria e publicação inicial neste periódico desde que adotem a mesma licença, compartilhar igual. Os autores têm autorização para assumir contratos adicionais separadamente, para distribuição não exclusiva da versão do trabalho publicada neste periódico (ex.: publicar em repositório institucional, em site pessoal, publicar uma tradução, ou como capítulo de livro), com reconhecimento de autoria e publicação inicial neste periódico, desde que para fins não comerciais e compartilhar com a mesma licença.

\section{PUBLISHER}

Universidade Federal de Santa Catarina. Programa de Pós-Graduação em Educação Física. LaboMídia - Laboratório e Observatório da Mídia Esportiva. Publicado no Portal de Periódicos

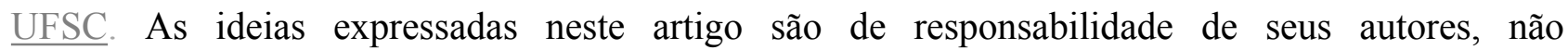
representando, necessariamente, a opinião dos editores ou da universidade.

\section{EDITORES}

Mauricio Roberto da Silva, Giovani de Lorenzi Pires, Rogério Santos Pereira.

\section{HISTÓRICO}

Recebido em: Março/2018

Aprovado em: Maio/2018 